\title{
Hard Capsule plus Tablet Dosage Form
}

National Cancer Institute

\section{Source}

National Cancer Institute. Hard Capsule plus Tablet Dosage Form. NCI Thesaurus. Code C149366.

Combination package consisting of a hard capsule and a tablet. 